American Journal of Applied Sciences 7 (10): 1400-1405, 2010

ISSN 1546-9239

(C) 2010 Science Publications

\title{
A New Development in Biological Process for Wastewater Treatment to Produce Renewable Fuel
}

\author{
${ }^{1}$ Kadhum M. Shabeeb, ${ }^{2}$ Khalid A. Sukkar, ${ }^{2}$ Rana A. Azeez, ${ }^{2}$ Najat J. Salah ${ }^{2}$ \\ ${ }^{2}$ Mummtas A. Yousif, ${ }^{2}$ Niran Manoual and ${ }^{2}$ Abyer Samir \\ ${ }^{1}$ Faculty of Chemical and Natural Resources Engineering, \\ University Malaysia Pahang, Kuantan, Malaysia \\ ${ }^{2}$ Department of Chemical Engineering, University of Technology, Baghdad, Iraq
}

\begin{abstract}
Problem statement: Hydrogen is a clean energy source. Bio-conversion of biomass to generate hydrogen has been achieved using anaerobic fermentation of some well-defined materials, in wastewater. No data available on hydrogen yielded from wastewater using inoculum extracted from Iraqi municipal wastewater treatment plant. Approach: This study investigated the effects of substrate concentration, initial $\mathrm{pH}$ and process temperature on biohydrogen production from surgery wastewater using anaerobic batch reactor. Batch tests are carried out in a $2.0 \mathrm{~L}$ batch reactor under different temperatures of $34,36,38$ and $40^{\circ} \mathrm{C}$, various initial $\mathrm{pH}$ of $4.5,5.5$ and 6.5 and substrate concentrations of 5,10 and $15 \%$. The raw seed was compost sludge obtained from municipal wastewater treatment plant in Baghdad (Al-Restomia plant). The volume of evolved gas was measured at room temperature by the water displacement method. Results: The maximum hydrogen production $160 \mathrm{~mL} \mathrm{~L}^{-1}$ is obtained at an optimum temperature of $38{ }^{\circ} \mathrm{C}$, optimum $\mathrm{pH}$ of 5.5 and substrate concentration $15 \%$. Conclusion: The results indicated that the use of compost of Al-Restomia plant as a seed in anaerobic fermentation process has given excellent biogas production under applied conditions.
\end{abstract}

Key words: Biological wastewater treatment, anaerobic fermentation, compost, biogas

\section{INTRODUCTION}

The use of fossil fuels leads to a serious threat to our environment. The combustion of fossil fuels brings about severe pollution and contributes to the greenhouse effect. In recent years, a great deal of attention is being paid to the utilization of biogas or hydrogen as alternative and friendly fuel throughout the world (Ronald, 1996; Zhang et al., 2007).

Compared with fossil fuels, biogas and hydrogen have the advantages of being renewable, providing clean burning and producing no greenhouse gases. There are several methods in industry available to produce biogas and hydrogen from organic and inorganic molecules. Some of these methods include electrolysis, reformation of hydrocarbons and microbiological methods. Many of these methods for generating hydrogen are difficult to use on a large scale because of the large amounts of energy required to produce the gas (Lee et al., 2004; 2009; Hawkes et al., 2007).

In general, hydrogen production by microorganism falls into two main categories: First, by means of photosynthetic processes involving organisms cultured under anaerobic light conditions (Hawkes et al., 2007; Lee et al., 2009; Li et al., 2007); second, via fermentation (Wang et al., 2003; Fang et al., 2002; Liu and Fang, 2003). Biological hydrogen production from the fermentation of renewable substrates is one promising process. On the other hand, the standard technology for industrial and municipal wastewater treatment is the aerobic activated sludge process. Sewage sludge is the total solid material that results from sedimentation and bacterial activity and growth during aerobic wastewater treatment (Thompson et al., 2008; Ren et al., 1997).

Methanogenic anaerobic digestion of organic material in wastewater has been performed for about a century and is advantageous over aerobic active sludge systems because of its high organic removal rates, low energy-input requirement, energy production (i.e., methane) and low sludge production. Wang et al. (2003) conducted the first systematic study on the production of hydrogen from wastewater sludge and found a rather high hydrogen yield from wastewater sludge using a clostridium strain isolated from the

Corresponding Author: Kadhum M. Shabeeb, Faculty of Chemical and Natural Resources Engineering, University Malaysia Pahang, Kuantan, Malaysia 
Am. J. Applied Sci., 7 (10): 1400-1405, 2010

sludge sample. Various bacteria have been found to convert carbohydrates to hydrogen. However, most of these studies have been carried out on pure cultures of isolated strains (Lee et al., 2009; Ren et al., 1997; Lin et al., 2008; Levin et al., 2004).

According to the explanation of Chang and Lin (2004) and Yang et al. (2006), the process of anaerobic digestion consists of three steps. The first step is hydrolysis, whereby biomasses are broken down in organic compound to smaller usable-size molecules. The second step is the conversion of decomposed matter to organic acid material. During the acidogenic phase of an aerobically digesting of sludge, hydrogen gas is produced. It is during the actual anaerobic when a gas principally composed of methane $\mathrm{CH}_{4}$ and carbon dioxide $\mathrm{CO}_{2}$ otherwise known as biogas, is produced. The amount of gas produced varies with the amount of organic waste fed to the digester and temperature influences the rate of decomposition (and gas production). In the anaerobic digester, hydrogen utilizing methanogenic bacteria are present and will consume the hydrogen that are produced during the acidogenic stage. The methanogenic bacteria utilize the hydrogen to create methane. Therefore, it is essential to slow down or stop the production of methanogenic bacteria in the anaerobic digester so that the hydrogen can be retained and extracted during the second step of the process (Hawkes et al., 2007; Ren et al., 1997).

Therefore, the main purposes of this study are to:

- Provide a basic understanding of anaerobic wastewater treatment process for wastewater with modify seed

- Study the effect of different operating parameters, such as: concentration of organic matters, temperatures and $\mathrm{pH}$ values on the biogas generation via anaerobic fermentation process

\section{MATERIALS AND METHODS}

Various types of chemical compounds are used in the present study: Glucose (99.9\%), $\mathrm{NaOH}, \mathrm{HCl}$ and nutrient stock (Fluka AG). The composition of the nutrient stock that was used in present study is shown in Table 1.

In the present study; the wastewater was prepared using tap water to produce distilled water through two time distillation at $120^{\circ} \mathrm{C}$ for 3 . The distilled water was cooled and stored in plastic storage tank. Three types of solutions were prepared depending on glucose concentrations of 5,10 and $15 \%$. The general specifications of the solutions (wastewater) are shown in Table 2.
Table 1: The composition of prepared nutrient stock solution (mixture) that is dissolved in 1 liter of distilled water

\begin{tabular}{lc}
\hline Nutrient & Weight $(\mathrm{g})$ \\
\hline $\mathrm{NH}_{4} \mathrm{HCO}_{3}$ & 200.00 \\
$\mathrm{KH}_{2} \mathrm{PO}_{4}$ & 100.00 \\
$\mathrm{CaCl}_{2} \cdot 2 \mathrm{H}_{2} \mathrm{O}$ & 10.00 \\
$\mathrm{MgSO}_{4} \cdot 7 \mathrm{H}_{2} \mathrm{O}$ & 10.00 \\
$\mathrm{NaCl}$ & 1.00 \\
$\mathrm{Na}_{2} \mathrm{MoO}_{4} \cdot 2 \mathrm{H}_{2} \mathrm{O}$ & 1.00 \\
$\mathrm{MnSO}_{4} \cdot 7 \mathrm{H}_{2} \mathrm{O}$ & 1.50 \\
$\mathrm{FeCl}_{2}$ & 0.25 \\
\hline
\end{tabular}

Table 2: General specifications of prepared wastewater

\begin{tabular}{llll}
\hline Property & $5 \%$ glucose & $10 \%$ glucose & $15 \%$ glucose \\
\hline $\mathrm{pH}$ & 6.8 & 6.7 & 6.3 \\
$\begin{array}{l}\text { Chemical Oxygen } \\
\text { Demand (COD) mg L }\end{array}$ & 850 & 1400 & 1660 \\
$\begin{array}{l}\text { Total Dissolved Solid } \\
\left(\text { TDS } \mathrm{mg} \mathrm{L}^{-1}\right.\end{array}$ & 340 & 300 & 250 \\
Conductivity $\left(\mu \mathrm{s} \mathrm{cm}^{-1}\right)$ & 490 & 420 & 340 \\
\hline
\end{tabular}

Conductivity $\left(\mu \mathrm{s} \mathrm{cm}^{-1}\right) \quad 490 \quad 420 \quad 340$

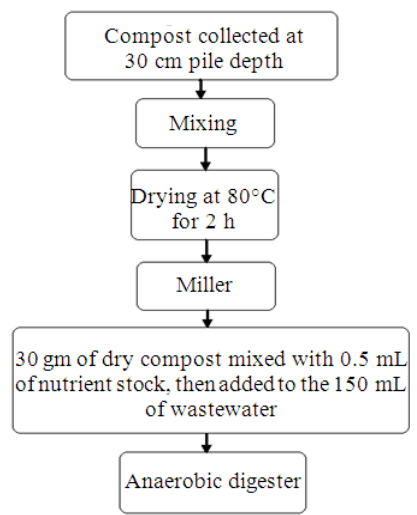

Fig. 1: Preparation and pretreatment procedure of compost for the fermentation

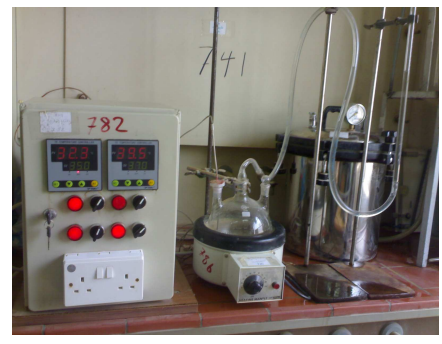

Fig. 2: General view of experimental unit

The raw seed was compost sludge obtained from municipal wastewater treatment plant in Baghdad (AlRestomia plant). Figure 1 summarizes the general pretreatment procedure that was used for compost before the anaerobic fermentation process. For each experiment $30 \mathrm{~g}$ of this compost was used as a seed (microorganism) for the anaerobic fermentation process and treated with $0.5 \mathrm{~mL}$ of nutrient solution. 
In the present study, batch anaerobic experiments were used. Figure 2 shows the general view of experimental unit, while Fig. 3 shows a schematic diagram apparatus. The digester used in this study was $2 \mathrm{~L}$ spherical flask glass with three necks as shown in Fig. 2. The digester was connected to a gas collection system consisting of U-tube manometer. The volume of evolved gas was measured at room temperature by the water displacement method in the U-tube manometer that had been filled with water of $\mathrm{pH} 3$ or less in order to prevent dissolution of the gas components. The digester was placed over a magnetic plate stirrer in order to ensure adequate mixing during the process. The whole set of experiments was carried out under the same stirring condition (same magnetic stirring bar and stirring speed). On the other hand, the temperature at the digester center was determined and controlled using temperature control system which has calibrated thermocouple sensor type $\mathrm{T}$ (copper-constantan). The fermentation process was carried out under different operating temperatures of $34,36,38$ and $40^{\circ} \mathrm{C}$. The $\mathrm{pH}$ value of the mixture was controlled through the addition of $3 \mathrm{M}$ of $\mathrm{NaOH}$ or $3 \mathrm{M}$ of $\mathrm{HCl}$ to digester before each run. Different $\mathrm{pH}$ values 4.5, 5.5 and 6.5 were selected for experiments.

Biogas production was measured from the total volumes of biogas produced. Before each run the digester was aerated by nitrogen gas to remove the dissolved oxygen in order to alter the aerobic sludge stabilization during the experiments. The experiments were terminated when no significant gas production was observed over a seven day period, where, after that a death zone (phase) present in growth curve. This final phase is not important in process design study. On the other hand, the Chemical Oxygen Demand (COD) was determined.

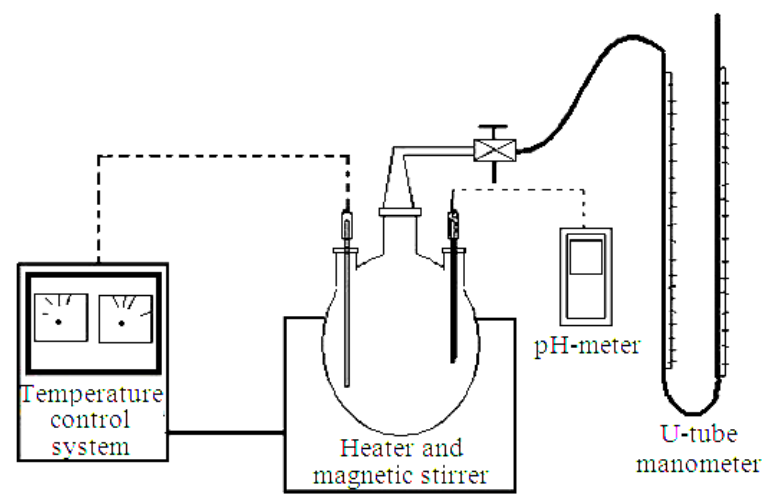

Fig. 3: Schematic diagram of biogas production system
The compost sample was sterilized in a furnace. The thermal pretreatment was selected as $80^{\circ} \mathrm{C}$ and 30 min of treatment time. This type of the pretreatment is important to be ensuring from killing all undesirable bacteria (aerobic bacteria) (Wang et al., 2003; Chang and Lin, 2004). After sterilizing, the pretreated sterilized compost sample was cooled to ambient temperature and treated with $0.5 \mathrm{ml}$ of nutrient solution and then was used in experiments.

\section{RESULTS AND DISCUSSION}

The prepared wastewater samples were an aerobically digested in a closed reactor using compost seed. The volume of biogas production was monitored under different $\mathrm{pH}$ values, temperatures and concentration of organic materials. Therefore, the results in the present study suggest that the digestion of wastewater produce $\mathrm{H}_{2}, \mathrm{CH}_{4}, \mathrm{CO}_{2}$ and other products such as alcohols as shown in the following equation:

$$
\begin{gathered}
\text { Wastewter Contain } \\
\stackrel{\text { Angaerobic }}{\longrightarrow} \text { Hydrogen gas }+ \\
\mathrm{CH}_{4}+\mathrm{Co}_{2}+\underset{\text { products }}{\text { Other end }}
\end{gathered}
$$

Therefore, in order to increase the biogas and hydrogen gas production, many parameters must be studied to get the best operating conditions for anaerobic digestion process as follows.

Effect of $\mathrm{pH}$ value on fermentation process: Different $\mathrm{pH}$ values ranging from 4.5-6.5 were used in the present study under batch operation mode. The relationships between the biogas production and fermentation time under different values of $\mathrm{pH}$ and glucose concentrations are shown in Fig. 4-6.

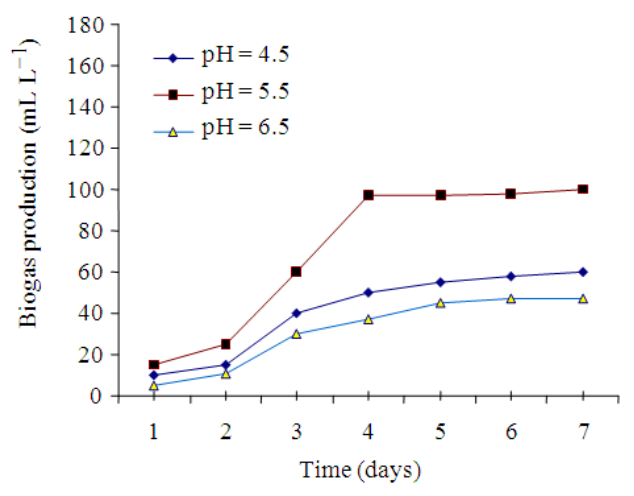

Fig. 4: Biogas production within 7 days of batch anaerobic fermentation performed at $38^{\circ} \mathrm{C}$ and $5 \%$ Glucose at different $\mathrm{pH}$ values 


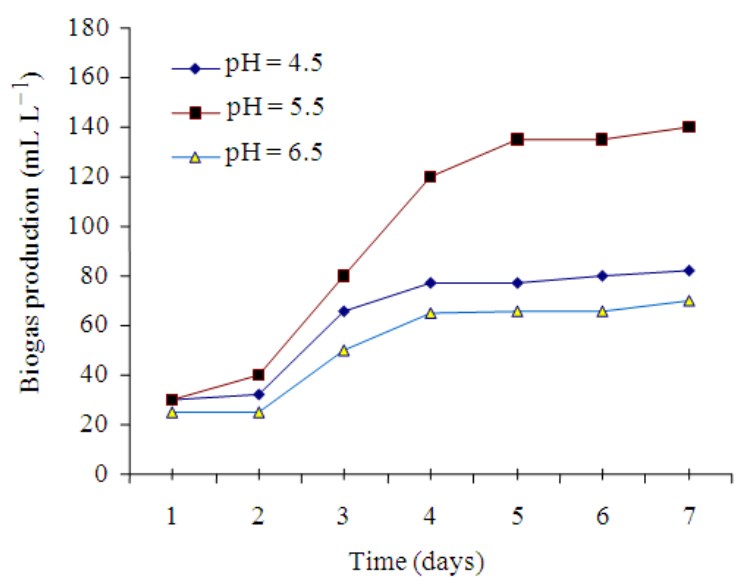

Fig. 5: Biogas production within 7 days of batch anaerobic fermentation performed at $38^{\circ} \mathrm{C}$ and $10 \%$ Glucose at different $\mathrm{pH}$

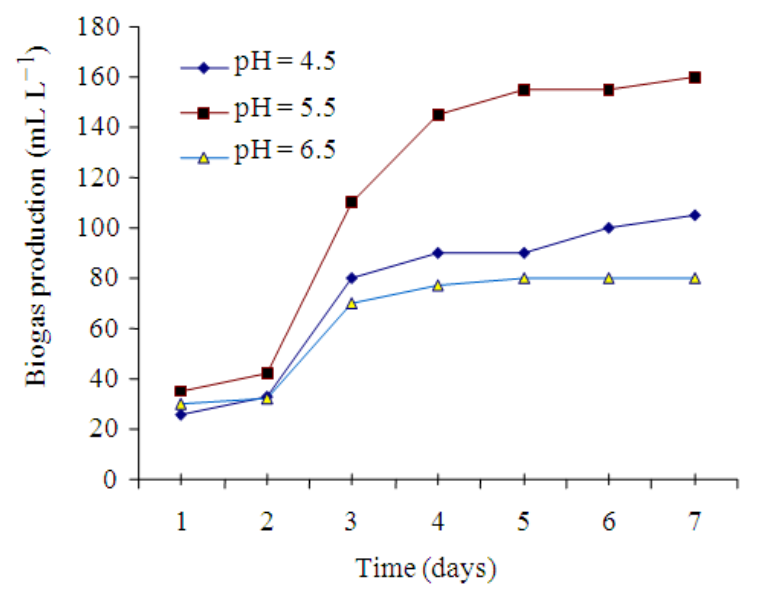

Fig. 6: Biogas production within 7 days of batch anaerobic fermentation performed at $38^{\circ} \mathrm{C}$ and $15 \%$ glucose at different $\mathrm{pH}(4.5,5.5$ and 6.5$)$

From the accumulated biogas volume, it was noted that the type of microorganism that was used in this investigation has worked successfully under anaerobic condition. This indicates that the used compost is rich in anaerobic microorganism (bacteria). Such type of bacteria plays an important role in hydrogen gas production under anaerobic condition. This conclusion is in accord with the study of Levin et al. (2004) and Thompson et al. (2008). Therefore, the present study was focused on the pretreatment condition that was applied to the compost seed in order to ensure the growth of the desired bacteria which is responsible for generating hydrogen gas and reducing methane formation.
Also, from Fig. 4-6 it is found that the $\mathrm{pH}$ value of 5.5 gives the highest biogas production in all glucose concentrations of 5,10and $15 \%$. This indicates that the applied pretreatment conditions were successfully generating a more active and selective bacteria for the hydrocarbons that are present in wastewater under anaerobic conditions. The first zone (first $30 \mathrm{~h}$ ) of this curve represents the lag phase that is required by the bacteria to culminate in the new environment. The second zone of these curves represents the growth phase. It is important to mention here that this phase is named operating (or working) region in which behaves exponentially and it is important for design study for such type of anaerobic process. Also, it was noted that as the concentration of glucose increases the biogas production increases too.

It was noted that after 6-7 days of fermentation time there was no further gas generation was detected, therefore, the death zone started after 7 days. It is important to mention here that the present study has focused on the operating zone which lies between 2-6 days. The highest biogas production was achieved at $15 \%$ glucose of about $160 \mathrm{~mL} \mathrm{~L}^{-1}$ at $5.5 \mathrm{of} \mathrm{pH}$ value.

It is important to mention here that with $\mathrm{pH}$ values lower than 5 or higher than 6 , the methanogenesis rate decreases or stops according to explanations of Chang and Lin (2004) and Yang et al. (2006). Consequently, in the present study it was concluded that the use of $\mathrm{pH}$ value of 5.5 prevents hydrogen reduction and produces dominant microbes for hydrogen production from wastewater.

Effect of temperature on fermentation process: According to the explanation of Zhang et al. (2007) the anaerobic fermentation process is greatly influenced by many factors, such as $\mathrm{pH}$, temperature, concentration and nutritional requirements. Temperature is one of the important factors influencing the biogas production process. Therefore, substrate degradation, $\mathrm{H}_{2}$ production, product distribution and bacterial growth are all affected by temperature. The $\mathrm{pH}$ value was kept constant at $5.5( \pm 0.2)$. Figure $7-9$ show the effect of digestion temperature on the biogas production rate. Four ranges of temperatures were applied $(34,36,38$ and $40^{\circ} \mathrm{C}$ ). The results of Fig. 7-9 show that the best operating temperature for digester is $38^{\circ} \mathrm{C}$ which shows the highest biogas production. This conclusion indicates that the real growth and activity of the anaerobic microorganism is related to suitable $\mathrm{pH}$ and temperature values. The biogas production rates were 115, 133 and $160 \mathrm{~mL} \mathrm{~L}^{-1}$ for glucose concentrations of 5, 10and 15\% respectively. This conclusion agrees with the investigation of Lee et al. (2004) and Wang et al. (2003). 


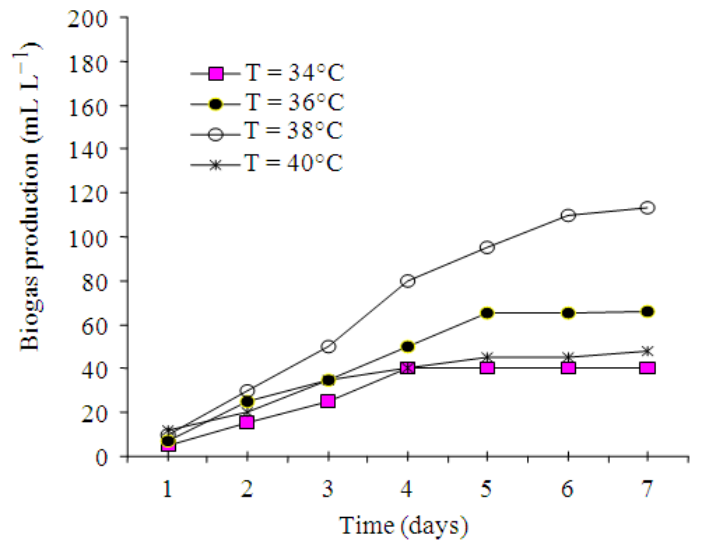

Fig. 7: The effect of temperature variation on biogas production at $5 \%$ of Glucose concentration and $5.5 \mathrm{pH}$

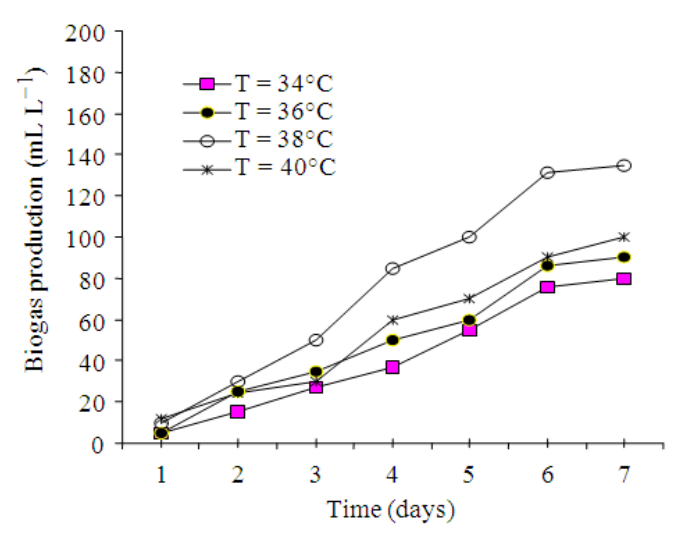

Fig. 8: The effect of temperature variation on biogas production at $10 \%$ of Glucose and $5.5 \mathrm{pH}$ value

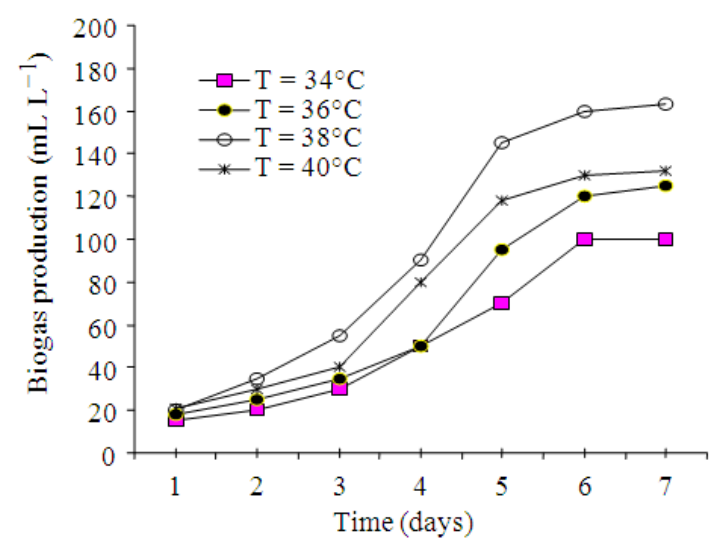

Fig. 9: The effect of temperature variation on biogas production at $15 \%$ of Glucose concentration and $5.5 \mathrm{pH}$ value
It is important to mention here that the anaerobic digestion is a complex biochemical reaction carried out in the presence of special types of microorganisms that require no oxygen to live. Clostridium is an important anaerobic hydrogen-producing microorganism. In the acidogenic phase of anaerobically digesting organic wastes are usually produced of hydrogen gas (Levin et al., 2004; Chang and Lin, 2004). In general, the anaerobic digestion process can be divided into three main steps (Hawkes et al., 2007; Ronald, 1996; Ren et al., 1997):

- Hydrolysis, during which the proteins, cellulose, lipids and other complex organics are broken down into smaller molecules and become soluble by utilizing water to split the chemical bonds of the substances

- Volatile acid fermentation, during which the products of hydrolysis are converted into organic acids through the biochemical processes of acid genesis (where monomers are converted to fatty acids) and cytogenesis (the fatty acids are converted to acetic acid, carbon dioxide and hydrogen)

- Methane formation, during which the organic acids produced during the fermentation step are converted to methane and carbon dioxide

\section{CONCLUSION}

The present study has focused on modifying the anaerobic digestion process to produce biogas (hydrogen gas) via the selection of the best pretreatment methods for seed and best operating conditions of $\mathrm{pH}$, temperature and nutrient composition. The use of compost in anaerobic fermentation process, has given excellent biogas production. In addition, this process shows a great potential for economical production of renewable gas fuel. The results show that the $\mathrm{pH}$ value of 5.5 is suitable for biogas production, when the highest conversion efficiency is achieved. The results indicate that the best operating temperature for all concentrations of glucose was $38^{\circ} \mathrm{C}$. This temperature gives the highest biogas production.

\section{REFERENCES}

Chang, F.Y. and C.Y. Lin, 2004. Biohydrogen production using an up-flow anaerobic sludge blanket reactor. Int. J. Hydrogen Energy, 29: 33-39. DOI: 10.1016/S0360-3199(03)00082-X

Fang, H.H.P., H. Liu and T. Zhang, 2002. Characterization of a hydrogen-producing granular sludge. Biotechnol. Bioeng., 78: 44-52. DOI: 10.1002/bit.10174 
Hawkes, F.R., I. Hussy, G. Kyazze, R. Dinsdale and D.L. Hawkes, 2007. Continuous dark fermentative hydrogen production by mesophilic microflora: Principles and progress. Int. J. Hydrogen Energy, 32: 172-84. DOI: 10.1016/j.ijhydene.2006.08.014

Lee, D.Y., Y.Y. Li and T. Noike, 2009. Continuous $\mathrm{H}_{2}$ production by anaerobic mixed microflora in membrane bioreactor. Bioresour. Technol., 100: 690-695. DOI: 10.1016/j.biortech.2008.06.056

Lee, K.S., J.F. Wu, Y.S. Lo, Y.C. Lo and P.J. Lin et al., 2004. Anaerobic hydrogen production with an efficient carrier-induced granular sludge bed bioreactor. Biotechnol. Bioeng, 87: 648-657. DOI: 10.1002/bit.20174

Levin, D.B., L. Pitt and M. Love, 2004. Biohydrogen production: prospects and limitations to practical application, Int. J. Hydrogen Energy, 29: 173-185. DOI: 10.1016/S0360-3199(03)00094-6

Li, J.Z., B.K. Li, G.F. Zhu, N.Q. Ren and L.X. Bo et al., 2007. Hydrogen production from diluted molasses by anaerobic hydrogen producing bacteria in an Anaerobic Baffled Reactor (ABR). Int. J. Hydrogen Energy, 32: 3274-3283. DOI: 10.1016/j.jijhydene.2007.04.023

Lin, C.Y., C.C. Wu and C.H. Hung, 2008. Temperature effects on fermentative hydrogen production from xylose using mixed anaerobic culture. Int. J. Hydrogen Energy, 33: 43-50. DOI: 10.1016/j.ijhydene.2007.09.001

Liu, H. and H.H. Fang, 2003. Hydrogen production from wastewater by acidogenic granular sludge. Water Sci. Technol., 47: 153-158. PMID: 12578188
Ren, N., B. Wang and J.C. Huang, 1997. Ethanol-type fermentation from carbohydrate in high rate acidogenic reactor. Biotechnol. Bioeng., 54: 428-433. PMID: 18634135

Ronald, L.D., 1996. Theory and Practice of Water and Wastewater Treatment. 1st Edn., Wiley, USA., ISBN: 978-0471124443, pp: 816.

Thompson, L.J., V.M. Gray, B. Kalala, D. Lindsay and K. Reynolds et al., 2008. Biohydrogen production by Enterobacter cloacae and Citrobacter freundii in carrier induced granules. Biotechnol. Lett., 30: 271-274. DOI: 10.1007/s10529-007-9527-y

Wang, C.C., C.W. Chang, C.P. Chu, D.J. Lee and B.V. Chang et al., 2003. Producing hydrogen from wastewater sludge by Clostridium bifermentans. J. Biotechnol., 102: 83-92. DOI: 10.1016/S01681656(03)00007-5

Yang, H., P. Shao, T. Lu, J. Shen and D. Wang et al., 2006. Continuous biohydrogen production from citric acid wastewater via facultative anaerobic bacteria. Int. J. Hydrogen Energy, 31: 1306-1313. DOI: 10.1016/j.ijhydene.2005.11.018

Zhang, Z.P., J.H. Tay, K.Y. Show, R. Yan and D.T. Liang et al., 2007. Biohydrogen production in a granular activated carbon anaerobic fluidized bed reactor. Int. J. Hydrogen Energy, 32: 185-191. DOI: 10.1016/j.ijhydene.2006.08.017 